\title{
A ESTRUTURA "ENTRETANTO" NO GÊNERO RESUMO ACADÊMICO: DE CONJUNÇÃO ADVERSATIVA A ELEMENTO ATIVADOR DE POLIFONIA
}

\author{
Marcos Antônio da Silva ${ }^{1}$
}

\begin{abstract}
RESUMO: O presente trabalho tem o objetivo de analisar a estrutura linguística entretanto em quatro resumos acadêmicos. Para tal empreendimento, lançamos mão da Teoria da Argumentação na Língua postulada por Anscombre e Ducrot (1994) e Ducrot (1988), dentre outros. Nessa teoria, esse operador funciona como orientador dos discursos que possibilitam ao leitor produzir determinadas conclusões. A análise realizada no corpus constatou que o uso do operador argumentativo entretanto, no gênero resumo acadêmico, apresenta-se como principal estratégia argumentativa. Além disso, o operador analisado não funciona apenas como elemento de ligação de palavras e orações, mas também ativa pontos de vista diferentes, revelando o posicionamento do locutor responsável pelo texto.
\end{abstract}

PALAVRAS-CHAVE: Argumentação. Operador argumentativo. Resumo acadêmico. Polifonia.

\section{INTRODUÇÃO}

Algumas estruturas linguísticas, como é o caso do elemento, "entretanto", são apresentadas comumente pelas gramáticas tradicionais, e por diversos manuais didáticos, como conjunções coordenativas, cuja função é a de unir termos sintaticamente equivalentes. Indo em direção contrária ao que é proposto por tais gramáticas e manuais, estudiosos da Semântica Argumentativa observam essas estruturas como 'operadores argumentativos', sendo, portanto, elementos que têm o papel de orientar os enunciados para conclusões diferentes.

Este artigo, que partilha de uma visão de língua enquanto processo de interação entre os falantes, tem como objetivo apresentar uma breve análise do operador "entretanto", a partir de uma visada semântico-argumentativa, em quatro resumos acadêmicos. Para nossa empreitada, analisaremos e descreveremos, então, a forma de funcionamento da referida estrutura linguística nos textos já aludidos, textos esses tidos como "objetivos" pelos manuais oficiais.

O corpus utilizado para análise, neste texto, trata-se de um recorte de uma tese de doutorado que objetivou realizar uma análise semânticoargumentativa dos operadores de contraposição no gênero resumo acadêmico. Salientamos, dessa maneira, que o este texto está dividido da seguinte forma: apresentação da teoria que dará suporte à discussão sobre nosso objeto de

\footnotetext{
${ }^{1}$ Doutor em Linguística pelo Programa de Pós-Graduação em Linguística da Universidade Federal da Paraíba, PROLING-UFPB. Professor efetivo de Língua Portuguesa do Instituto Federal de Alagoas, campus Murici. E-mail: marco_sil2@hotmail.com.
} 
análise, nesse caso, a Teoria da Argumentação na Língua; breves comentários sobre o fenômeno da polifonia na linguística; alguns apontamentos sobre os operadores argumentativos; rápido debate sobre o gênero resumo acadêmico; análises do nosso corpus e, por fim, as considerações finais que encerram nosso empreendimento.

\section{A TEORIA DA ARGUMENTAÇÃO NA LÍNGUA}

A Teoria da Argumentação na Língua, à qual nos filiamos, percebe a argumentação como algo inerente à língua (ANSCOMBRE e DUCROT, 1994). Esta concepção está vinculada ao fato destes dois estudiosos verificarem que há, na significação de determinados enunciados, orientações de natureza argumentativa.

Os estudos sobre a argumentação na língua surgiram a partir da necessidade de uma teoria que repensasse a noção percebida, tradicionalmente, em relação ao sentido de um enunciado. Assim, a Teoria da Argumentação na Língua tem "[...] como principal objetivo se opor à noção tradicional de sentido" (DUCROT, 1988, p. 49).

Para tal oposição, foram traçadas algumas considerações a respeito da noção de sentido. Dessa forma, enquanto a noção tradicional de sentido postula que um enunciado apresenta três indicações de sentido, a saber: objetivas (com a função de descrever algo da realidade), subjetivas (que revela a intenção do falante), e intersubjetivas (o efeito provocado pelo falante nos interlocutores), os estudiosos fundadores da Teoria da Argumentação na Língua propõem que, "[...] se a realidade é descrita através da linguagem, essa forma de descrevê-la se dá por meio dos aspectos subjetivos e intersubjetivos [...]" (ANSCOMBRE e DUCROT, 1994, p. 51), que os esses dois estudiosos reúnem e denominam de o "valor argumentativo dos enunciados".

Pensando, pois, já em uma abordagem sobre os operadores argumentativos, é postulado nessa teoria que "O valor argumentativo de uma palavra é, por definição, a orientação que essa palavra dá ao discurso" (DUCROT, 1988, p. 61). 
Dessa forma, percebendo que em todas as esferas sociais precisamos expor nossas opiniões, argumentar, discutir sobre fatos do cotidiano, e que todas essas ações são realizadas por meio da linguagem, acrescentamos ao nosso estudo a contribuição de que não apenas "[...] a língua é argumentativa" (ANSCOMBRE e DUCROT, 1994), mas que "[...] o uso também é argumentativo", (ESPÍNDOLA, 2004, p. 13).

Nesse sentido, ainda refletindo sobre a argumentatividade presente na própria estrutura da língua, é relevante destacar que "[...] a interação social por intermédio da língua caracteriza-se, fundamentalmente, pela argumentatividade", $(\mathrm{KOCH}, 2004$, p. 17). Essa interação - ação verbal - é marcada por uma intenção, pois quem fala tem um objetivo para com o outro, seja para prender sua atenção, convencer o outro a fazer algo, opor-se ao outro ou impor seu ponto de vista sobre o outro.

Assim sendo, diante dos breves pressupostos aqui apresentados, é pertinente dizer que argumentar é orientar o discurso que será proferido/exposto ao nosso interlocutor, tendo em vista os objetivos do locutor. Ademais, é importante salientar que tais orientações argumentativas são construídas enunciativamente, justamente porque "[...] certas palavras, em certas circunstâncias, são dotadas de eficácia" (DUCROT, (1987, p. 163).

\subsection{0 fenômeno da polifonia: da literatura à linguística}

Utilizado para se referir a um tipo de composição musical na qual ocorre uma superposição de vozes, o termo polifonia foi originalmente utilizado nos estudos literários pelo teórico russo Mikhail Bakhtin (1997) para diferenciar dois tipos de literatura: a literatura dogmática e a literatura polifônica ou carnavalesca.

Explicitamos que a literatura dogmática ocorre quando há a presença de apenas uma única voz ou ainda quando o autor decide/julga o pensamento da personagem. Como exemplos desse tipo de literatura, o estudioso propõe o ensaio e a exposição teórica. Por sua vez, a literatura polifônica ou carnavalesca ocorre quando as inúmeras personagens existentes em um romance, por exemplo, apresentam-se por si mesmas, ou seja, têm vidas próprias. O melhor exemplo de literatura polifônica é a obra de Dostoiévski (DUCROT, 1988). 
Quando da utilização da noção de polifonia nos estudos linguísticos, ocorre também a distinção entre dois tipos de polifonia: a polifonia de locutores e a polifonia de enunciadores. O primeiro tipo ocorre, geralmente, no discurso relatado no estilo direto, indireto ou indireto livre. Encontramos polifonia de locutores em exemplos como: "Pedro me disse: eu irei amanhã", (DUCROT, 1988, p. 55). Nesse exemplo, o primeiro enunciado pertence ao locutor $L 1$ e o segundo enunciado ao locutor L2. O que acontece é que o locutor L1 produz seu enunciado e recupera o enunciado produzido por L2, fundindo-os em um só acontecimento enunciativo. Além disso, podemos perceber que as marcas linguísticas, como os pronomes "me" e "eu", pertencem a produtores/locutores diferentes.

O segundo tipo ocorre quando em um mesmo enunciado há a presença de vários enunciadores, ou seja, vários pontos de vista diferentes. Assim, em um enunciado como "Tenho vontade de passear, mas tenho dor nos pés", (DUCROT, 1988 , p. 56), identificamos quatro pontos de vista, conforme se observa no esquema seguinte:

E1: Tenho vontade de passear;

E2: Irei passear/ ao passeio; (conclusão r)

E3: Mas tenho dor nos pés;

E4: Não irei passear. (conclusão não-r)

Após verificarmos que há quatro enunciadores ou pontos de vista nesse enunciado, observamos que a partir do enunciado E1 é certo concluir E2, e que com base em E3 podemos concluir E4, que por sua vez, enquanto conclusão, será contrária à elaborada em E2. Nesse caso, podemos afirmar que o locutor responsável por esse enunciado aprova $\mathrm{E} 1$, identifica-se com os enunciadores $\mathrm{E} 3$ e E4 e rechaça E2, que foi a primeira conclusão produzida com base apenas na primeira proposição E1.

Essas breves considerações sobre a polifonia se fizeram necessárias, pois nas análises do nosso corpus identificamos enunciados com a estrutura entretanto, que possui índice de polifonia, característica natural dos operadores de contraposição (DUCROT, 1988). 


\section{O ELEMENTO, "ENTRETANTO": DE CONJUNÇÃO ADVERSATIVA A OPERADOR ARGUMENTATIVO}

Apresentada como sendo uma classe gramatical, a conjunção é vista como "[...] a palavra invariável usada para ligar orações ou termos semelhantes (de mesma função sintática) de uma oração" (NICOLA E INFANTE, 1997, p. 232). Para esses dois autores, a palavra entretanto está presente nas orações coordenadas adversativas, bem como as estruturas do tipo: porém, contudo, todavia, mas e ainda as locuções no entanto, não obstante e nada obstante.

Ainda conforme os referidos autores, estruturas dessa natureza se fazem presentes nas sentenças da língua, introduzindo uma oração e exprimindo contraste, oposição ou compensação em relação à anterior. Como exemplo, os autores apresentam os seguintes enunciados: "Este mundo é redondo, mas está ficando muito chato", de Barão de Itararé, e "O amor é difícil, mas pode luzir em qualquer ponto da cidade", de Ferreira Gullar, (NICOLA e INFANTE, 1997, p. 302).

Ainda nesse mesmo caminho de definição das conjunções, encontramos o conceito de que "A língua possui unidades que têm por missão reunir orações num mesmo enunciado" (BECHARA, 2009, p. 319), classificadas tradicionalmente como conjunções coordenativas ou subordinativas. Aquelas têm como função reunir "[...] orações que pertencem ao mesmo nível sintático: dizem-se independentes umas das outras e, por isso mesmo, podem aparecer em enunciados separados" (BECHARA, 2009, p. 320).

Sobre as conjunções coordenativas adversativas, é possível encontrar posicionamentos que consideram essas estruturas como sendo elementos que têm como característica o fato de que "[...] enlaçam unidades apontando uma oposição entre elas" (BECHARA, 2009, p. 321). Ainda conforme exemplo explicitado pelo autor, temos: "Acabou-se o tempo das ressurreições, mas continua o das insurreições".

De acordo com o conceito colocado no exemplo supracitado, podemos entender que entre "acabar o tempo das ressurreições e continuar o das insurreições" ocorreria uma relação de oposição. Esse mesmo autor ainda considera as conjunções mas, porém e senão adversativas por excelência. A explicação para tal comportamento seria a seguinte: "Ao contrário das aditivas e 
alternativas, que podem enlaçar duas ou mais unidades, as adversativas se restringem a duas. Mas e porém acentuam a oposição; senão marca a incompatibilidade" (BECHARA, 2009, p. 321).

A partir de uma nova abordagem por parte da semântica-argumentativa, revelou-se que as conjunções, agora percebida como os operadores argumentativos, têm como função relacionar semanticamente elementos no interior do texto, e que são essenciais para a interpretação do mesmo. Assim:

A coesão, por estabelecer relações de sentido, diz respeito ao conjunto de recursos semânticos por meio dos quais uma sentença se liga com a que veio antes, aos recursos semânticos mobilizados com o propósito de criar textos. $(\mathrm{KOCH}, 1999$, p. 17).

Portanto, trata-se, na verdade, de um "elo coesivo" o funcionamento desses recursos linguísticos na produção textual. Dessa forma, ainda consoante essa autora, os operadores podem ser classificados da seguinte maneira:

a) Operadores que assinalam o argumento mais forte de uma escala orientada no sentido de determinada conclusão: até, mesmo, até mesmo, inclusive.

b) Operadores que somam argumentos a favor de uma mesma conclusão: e, também, ainda, nem, não só... mas também, tanto...como, além de..., além disso..., a par de... etc.

c) Operadores que introduzem uma conclusão relativa a argumentos apresentados em enunciados anteriores: portanto, logo, por conseguinte, pois, em decorrência, consequentemente etc.

d) Operadores que introduzem argumentos alternativos que levam a conclusões diferentes ou opostas: ou, ou então, quer...quer, seja...seja etc.

e) Operadores que estabelecem relações de comparação entre elementos, com vistas a uma dada conclusão: mais que, menos que, tão...como etc.

f) Operadores que introduzem uma justificativa ou explicação relativa ao enunciado anterior: porque, que, já que, pois etc.

g) Operadores que contrapõem argumentos orientados para conclusões contrárias: mas (porém, contudo, entretanto, todavia, no entanto, etc.), embora (ainda que, posto que, apesar de (que) etc.).

h) Operadores que tem por função introduzir no enunciado conteúdos pressupostos: já, ainda, agora, etc.

i) Operadores que se distribuem em escalas opostas, isto é, um deles funciona numa escala orientada para a afirmação total e o outro, numa escala orientada para a negação total: um pouco e pouco (KOCH, 2007, p. 31-38).

Como se percebe, a partir dos elementos destacados, o operador entretanto pertence ao grupo " $g$ ", ou seja, ao grupo dos operadores que 
contrapõem argumentos, orientando, dessa forma, os enunciados para conclusões opostas.

Alguns estudiosos que se preocuparam com o estudo dos operadores argumentativos, explicitam a existência de dois tipos de operadores de contraposição originários do mas: o masSN, cuja função é a de corrigir um enunciado apresentado anteriormente, como é o caso de "Ele não é jogador, mas médico"; e o masPA, responsável por apresentar polifonia de enunciadores (VOGT e DUCROT, 1980). Esses dois autores mencionados anteriormente não tratam especificamente do operador entretanto, mas, nesse caso, como o grupo de operadores que contrapõem argumentos orientados para conclusões contrárias permite a existência de outras estruturas, como embora, todavia, contudo etc, incluiremos, aqui, o operador entretanto como fazendo parte do mesmo nível de comportamento argumentativo dos demais operadores.

Sobre o fato de o masSN exigir que a proposição anterior seja negativa, tal ocorrência pode ser justificada a partir do fato de que esse operador aparece com a "[...] função de correção de algo suposta ou realmente dito antes [...]" (GUIMARÃES, 1987, p. 61-62).

No tocante ao masPA, os dois autores já citados fazem uma ressalva no que diz respeito a sua origem, pois o mesmo pode ter sido derivado do advérbio latino magis, como dito anteriormente, contudo, sendo usado somente no latim vulgar; ou o advérbio latino teria formado "[...] apenas o masSN que, em seguida, ter-se-ia estendido para preencher a função PA" (VOGT e DUCROT, 1980, p. 117).

Os operadores de contraposição, não apenas o mas, também podem funcionar como um índice de polifonia nos enunciados. Com a presença de um operador dessa natureza em um enunciado é possível não só identificar diferentes enunciadores, como também descrever o posicionamento do locutor responsável pelo discurso com relação a esses enunciadores.

Buscando traçar uma representação para as posições do locutor frente aos enunciadores, o criador da Teoria da Argumentação na Língua apresenta a partir de algumas análises de enunciados com a estrutura $X$ mas $Y$ as possíveis posições do locutor L. Ao final de suas análises, o pesquisador estabelece que: 
"[...] L rechaça siempre a E2 y se identifica com E4, es decir que el locutor siempre concluye no r. En quanto a E1 y E3 todo lo que podemos decir es que $L$ no los rechaça, en unos casos puede aprobarlos, en otros casos puede identificarse con ellos" (DUCROT, 1988, p. 69-71).

Assim, como pode ser observado na citação acima, esse autor afirma, como regra, que essas são as posições possíveis do locutor $L$ em relação aos enunciadores presentes nos enunciados. No entanto, são possíveis outros posicionamentos de $\mathrm{L}$ com relação a $E 2$, não previstos por essa teoria, como é o caso identificado e classificado como 'rechaço parcial' (SILVA, 2015), conforme veremos em nossas análises, posteriormente.

\section{O RESUMO ACADÊMICO}

Os gêneros são construídos nas diversas esferas sociais da comunicação/atividade humana (BAKHTIN, 2000). Pensando dessa forma, é possível dizer que os resumos são produtos que atendem a diversas necessidades presentes em nosso cotidiano. Assim, se alguém solicita que você conte o filme que acabou de assistir, naturalmente, você precisará fazer um resumo, bem como precisará fazê-lo caso o professor peça que se resuma um texto lido em determinado site, livro, revista ou jornal.

As principais formas de resumos produzidas em nossas atividades cotidianas são: resumo de telenovela, resumo de filme, resumo jornalístico de textos e resumo literário (SILVA e MATA 2002). Já no meio acadêmico, essas duas autoras afirmam que os principais tipos são: o resumo de tese ou dissertação, resumo de trabalhos para congressos e o resumo escolar.

O resumo de artigo científico tem por objetivo "[...] sumarizar, indicar e predizer, em um parágrafo curto, o conteúdo e a estrutura do texto integral que segue" (MOTTA-ROTH e HENDGES 2010, p. 152). Também seria a função do resumo ajudar o leitor no momento da pesquisa, visto que quanto mais completo for o resumo, mais informações o leitor encontrará sobre o assunto/tema que está pesquisando.

\footnotetext{
${ }^{2}$ [...] L rechaça sempre a E2 e se identifica com E4, quer dizer que o locutor sempre conclui não-r. Enquanto a E1 e E3 tudo que podemos dizer é que $L$ não os rechaça, em uns casos pode aproválos, em outros casos pode se identificar com eles. (Tradução nossa.)
} 
Assim sendo, ainda seria função do resumo acadêmico persuadir o leitor a ler o restante do texto, ou seja, o texto integral. Em se tratando do envio de um resumo para avaliação de pareceristas em um evento/congresso, quando da sua produção, aquele que deseja ter seu resumo aceito deve estar atento a algumas "condições/normas" dos eventos. Desse modo, é importante que o produtor do texto saiba que os resumos não podem ser feitos de qualquer forma, mas que apresentam estruturas quase de formulários, a saber: objetivos, marco teórico, metodologia, possíveis resultados, discussão e conclusão (considerações finais ou parciais).

É possível assinalar ainda, em relação ao resumo, levando em consideração o "uso e a função social do gênero", que:

\footnotetext{
É um gênero textual produzido e consumido pela comunidade acadêmica. Caracteriza-se como uma das práticas discursivas do mundo acadêmico/científico, cujo fim é o de apresentar, de forma breve, informações de cunho teórico e metodológico, sobre o trabalho que será apresentado em forma de comunicação, oficina, palestra, conferência ou minicurso. (SILVA e MATA, 2002, p. 127).
}

Dessa forma, a partir do exposto, é função do resumo apresentar pistas ao seu interlocutor, possibilitando, dessa maneira, um reconhecimento do assunto que será tratado/abordado no texto integral. Portanto, poderíamos pensar no resumo de artigo científico como sendo um cartão de visitas que o "vendedor" ao entregar ao seu "cliente", com o objetivo de vender seu produto (ter seu artigo aceito/aprovado), permite que este veja, em um primeiro momento, as principais qualidades de seu produto (texto/artigo).

Salientamos que, de certa forma, considerando a imprecisão no que tange à classificação dos tipos de resumos, e tendo em vista que tanto os resumos para congressos como aqueles publicados em revistas e sites especializados circulam no meio acadêmico, iremos denominar, aqui, de 'resumos acadêmicos' todas essas espécies de resumos, excluindo desse grupo, portanto, os resumos de telenovela e de filmes, tendo em vista sua função comunicativa no contexto em que circulam.

Considerando ainda o curto espaço para uma discussão mais ampla sobre tal gênero, passaremos, no próximo tópico, às análises da estrutura entretanto no gênero resumo acadêmico. 


\title{
4 ANÁLISES DO CORPUS
}

Antes de adentrarmos, de fato, às análises dos nossos quatro resumos, algumas considerações metodológicas devem ser expostas ao leitor, com o intuito de que sejam apresentados os caminhos traçados por nós neste texto. Cabe destacar, assim, que os resumos aqui analisados foram coletados entre os anos de 2010 e 2011 em diversos anais de congressos regionais, nacionais e internacionais disponíveis na internet, além de revistas e anais digitais de eventos.

Além disso, registramos que os títulos dos resumos e os nomes dos autores efetivos dos textos foram suprimidos, para evitar uma possível identificação. Some-se a isso o fato de que os dados aqui apresentados fazem parte de um projeto maior, uma tese de doutorado, que investigou o comportamento dos operadores de contraposição no gênero discursivo resumo acadêmico.

Destacamos ainda, de forma sucinta, que as análises têm um caráter descritivo-analítico e obedeceu a seguinte ordem de realização: coleta dos dados, leitura e identificação dos resumos, análise dos resumos com a presença de operadores de contraposição (no caso, aqui, o operador "entretanto") e, por fim, as análises e descrição dos comportamentos dos operadores identificados.

\section{Resumo 01:}

\begin{abstract}
O objetivo principal deste trabalho é discutir os aspectos geotécnicos das argilas siltosas profundas de Rio Grande - RS, dando-se ênfase à formulação de correlações entre propriedades, obtidas em ensaios simples de laboratório, usados para caracterização do solo, e parâmetros obtidos em sofisticados ensaios, como os de adensamento e de resistência que interessam aos projetos geotécnicos. São feitas comparações entre as correlações obtidas para a argila siltosa de Rio Grande e de outros pontos pesquisados da costa brasileira. Com estas correlações, pode-se identificar mais facilmente o comportamento do solo. Entretanto, deve-se considerar que elas não substituem os ensaios de laboratório e campo para definir os parâmetros de projeto.
\end{abstract}

Diante da leitura do primeiro resumo, temos a ocorrência de quatro enunciadores possibilitados pela presença do operador, "entretanto", a saber:

E1: Com estas correlações, pode-se identificar mais facilmente o comportamento do solo. 
E2: As correlações serão úteis para as análises dos solos.

E3: Entretanto, deve-se considerar que elas não substituem os ensaios de laboratório e campo para definir os parâmetros de projeto.

E4: Apenas as correlações não serão suficientes para as análises dos solos.

O locutor, diante dos quatro enunciadores, posiciona-se da seguinte maneira: aprova E1, rechaça parcialmente E2 e identifica-se com E3 e E4. O rechaço parcial ocorre pelo fato de o locutor entender que as correlações são úteis, mas que elas sozinhas não constituem elemento suficiente para uma análise concreta. Ou seja, é necessária a presença de outro (ou outros) elemento/s para uma análise efetiva. A aprovação e a identificação ocorrem pelo fato de o locutor do texto entender e aceitar tais pontos de vista como certos.

Resumo 02:

A literatura produzida em Pernambuco tem importante papel na constituição de uma literatura nacional, sem necessariamente deixar de assinalar um "lugar" especificamente seu no jogo de trocas culturais que compõe o mundo contemporâneo. Nessa fronteira entre o nacional e o local, entre o velho e o novo, entre o chão de cada um e o universal, inscreve-se a produção literária atual, matizando-se em dicções e vozes diferenciadas que materializam a lógica plural de nosso tempo. Entretanto, é possível também identificar constantes estéticas na proposta artística de alguns escritores importantes, que não negam essa pluralidade, mas a potencializam pela via de elementos permanentes, revelando intensos laços estéticos entre o contemporâneo e a alta modernidade. Assim, reunimos um conjunto de estudos que visam pensar a literatura atual feita em Pernambuco a partir de suas relações com a tradição, o jornalismo, a memória e o cânone literário. Artur de Ataíde explorará a força da voz poética de Alberto da Cunha Melo e suas ligações com o universo social e cultural que Ihe deram chão; Cristhiano Aguiar discutirá o significado e pertinência da memória na narrativa contemporânea; Eduardo César Maia sondará as relações entre crítica literária e jornalismo cultural; e, por fim, Fábio Andrade, analisará as tensões e conexões que presidem a poesia de Micheliny Verunschk em relação à obra canônica e formadora de João Cabral de Melo Neto.

Assim como no exemplo do resumo 01, aqui no resumo 02 temos mais uma vez a ocorrência do operador "entretanto". Ressaltamos que não nos interessará, por motivo de objetivo referente à temática do trabalho, a presença do operador "mas". 
Para o locutor do texto como um todo, há possibilidade de identificação das constantes estéticas na proposta artística de alguns escritores importantes, mas essas constantes estéticas não negam uma pluralidade existente, pelo contrário, potencializam essa pluralidade por intermédio de elementos permanentes.

Os quatro enunciadores serão percebidos, de forma mais efetiva, com a observação da distribuição desses pontos de vista no esquema seguinte:

E1: Nessa fronteira entre o nacional e o local, entre o velho e o novo, entre o chão de cada um e o universal, inscreve-se a produção literária atual, matizando-se em dicções e vozes diferenciadas que materializam a lógica plural de nosso tempo.

E2: A produção literária de Pernambuco revela-se diversificada.

E3: Entretanto, é possível também identificar constantes estéticas na proposta artística de alguns escritores importantes, que não negam essa pluralidade, mas a potencializam pela via de elementos permanentes, revelando intensos laços estéticos entre o contemporâneo e a alta modernidade.

E4: A produção literária em Pernambuco revela-se diversificada e também homogênea.

O locutor aprova E1, rechaça parcialmente E2 e identifica-se com E3 e E4. O rechaço parcial ocorre quando o locutor percebe que há uma certa pluralidade na produção literária pernambucana (E2), mas mesmo dentro dessa pluralidade há uma certa estabilidade. Ou seja, E2 não é rechaçado totalmente, mas apenas de forma parcial, tendo em vista que E2 e E4, de alguma forma, complementam-se. A aprovação com E1 e a identificação com E3 e E4 ocorrem pelo fato de o locutor responsável pelo texto como um todo perceber tais pontos de vista como possíveis e que, portanto, devem e podem ser aceitos.

Resumo 03:

O estudo da informação implícita por meio da avaliação laboviana visa a analisar as estratégias utilizadas pelo narrador para dar relevância à sua narração. Parte-se do pressuposto de que toda história deve conter avaliação para merecer ser contada e para justificar o tempo mais longo tomado. Este trabalho visa a analisar a avaliação implícita veiculada pelo envolvimento entre os interlocutores e deles com o texto. Pode se dizer que só há interação se houver um mínino de envolvimento considerado como o comprometimento dos participantes da interação com os 
objetivos comunicativos. O referencial teórico constitui-se de textos de Labov (1972, 1981, 1997, 2001, 2003), Koch (1990), Tannen 91982a, $1982 b, 1985,1987)$ e Marcuschi $(2000,2008)$, entre outros. Para efeito da pesquisa, o corpus foi constituído por quatro narrativas extraídas dos inquéritos tipo DID (diálogo entre informantes e documentador) e quatro dos inquéritos do tipo D2 (diálogo entre os informantes), pertencentes ao Projeto NURC - Recife. Entretanto, para esta apresentação, foram escolhidas apenas duas narrativas. Em todos os textos analisados, foram encontradas estratégias de envolvimento, dos mais variados tipos, que veiculam a avaliação implícita. A pesquisa demonstrou novamente que o envolvimento sendo um recurso importante na construção do sentido é também uma estratégia relevante de avaliação das narrativas, em ambos os tipos de inquéritos (DID e D2).

A análise do resumo 03 , para nós, difere das análises anteriores. Isso será explicado ao longo dos nossos apontamentos aqui.

Tomando como ponto de análise o trecho que tem início com "Para efeito da pesquisa, o corpus foi constituído por quatro narrativas extraídas dos inquéritos tipo DID (diálogo entre informantes e documentador) e quatro dos inquéritos do tipo D2 (diálogo entre os informantes), pertencentes ao Projeto NURC - Recife.", o interlocutor irá concluir que "serão apresentadas as quatro narrativas".

No entanto, com a inserção de um outro argumento/enunciado que tem início com o trecho "Entretanto, para esta apresentação, foram escolhidas apenas duas narrativas", o interlocutor precisa concluir que "não serão apresentadas as oito narrativas". Percebemos, portanto, que as duas conclusões presentes em E2 e E4 são totalmente contrárias e isso não é algo estranho, pois a função dos operadores de contraposição é, de acordo com a própria teoria aqui abarcada, justamente a de orientar os enunciados para conclusão que são distintas.

Os enunciadores presentes nesse enunciado podem ser vislumbrados no esquema que segue:

E1: Para efeito da pesquisa, o corpus foi constituído por quatro narrativas extraídas dos inquéritos tipo DID (diálogo entre informantes e documentador) e quatro dos inquéritos do tipo D2 (diálogo entre os informantes), pertencentes ao Projeto NURC - Recife.

E2: Serão apresentadas as 8 narrativas. 
E3: Entretanto, para esta apresentação, foram escolhidas apenas duas narrativas.

E4: Não serão apresentadas as 8 narrativas.

O locutor, dessa maneira, diante desses quatro enunciadores, reage da seguinte forma: rechaça totalmente E2, aprova E1, identifica-se com E3 e E4. Mais uma vez, o locutor entende que os pontos de vista presentes em E1, E3 e E4 devem ser aceitos, mas percebe que E2 deve ser rechaçado, justamente porque E2, enquanto conclusão elaborada com base em E1, irá ser contrária à conclusão produzida em E4. Esse caso específico de oposição total entre E2 e E4, presente no resumo 03, é o clássico exemplo demonstrado pela Teoria da Argumentação na Língua. No entanto, o que percebemos é que outros casos, como nas ocorrências dos resumos 01, 02 e 04, a seguir, que pode haver um rechaço parcial do locutor diante dos quatro enunciadores.

Resumo 04:

Nos estudos relacionados ao ensino de línguas estrangeiras, percebe-se a preocupação do professor em desenvolver estratégias de ensino que colaborem com o desenvolvimento efetivo das habilidades comunicativas (produção escrita, produção oral, compreensão auditiva e compreensão leitora) trabalhadas em sala de aula. Tais habilidades, segundo especialistas em ensino de línguas estrangeiras, devem ser trabalhadas numa perspectiva sociointeracionista, já que 0 aprendiz, nesta perspectiva, terá a oportunidade de interagir em situações reais de uso da língua. Entretanto, verifica-se, em determinadas práticas pedagógicas, a presença de atividades tradicionalistas que não contribuem com o processo de ensino-aprendizagem de um idioma. Diante deste fato, o presente trabalho tecerá reflexões acerca da Teoria da Mediação de Feuerstein (1994), e da perspectiva Sociointeracionista de Vygotsky (2003), apresentando uma análise, realizada em instituições públicas, no ano de 2009 , de duas aulas de conversação de professores de língua espanhola que evidenciam a prática do sócio-interacionismo e da teoria da mediação no desenvolvimento das competências comunicativas. Ao final da análise, verificou-se que o processo de desenvolvimento de tais habilidades se faz de maneira efetiva quando os aprendizes desenvolvem atividades em grupos e quando seu conhecimento de mundo e seu conhecimento enciclopédico são levados em consideração no processo de aprendizagem. Acredita-se, assim, que tal pesquisa reforça a necessidade do professor de línguas em desenvolver atividades comunicativas fundamentadas em perspectivas sociointeracionistas.

Partindo de uma apreciação do resumo 04, podemos pontuar os quatro enunciadores, como mostra o esquema seguinte: 
E1: Tais habilidades, segundo especialistas em ensino de línguas estrangeiras, devem ser trabalhadas numa perspectiva sociointeracionista, já que o aprendiz, nesta perspectiva, terá a oportunidade de interagir em situações reais de uso da língua

E2: A perspectiva sociointeracionista é trabalhada

E3: Entretanto, verifica-se, em determinadas práticas pedagógicas, a presença de atividades tradicionalistas que não contribuem com o processo de ensinoaprendizagem de um idioma.

E4: Não é sempre que a perspectiva sociointeracionista é trabalhada.

O locutor responsável por esse texto, mediante esses quatro enunciadores, assume o seguinte posicionamento: rechaça parcialmente E2, aprova E1, identifica-se com E3 e E4.

O rechaço parcial é justificado pela presença da expressão "verifica-se, em determinadas práticas pedagógicas, a presença de atividades tradicionalistas", que possibilita concluir que há, em algumas situações, um trabalho a partir de uma visão sociointeracionista. Nesse caso, é possível pontuar várias estruturas que funcionam como elementos modalizadores, a saber: "verifica-se", asseverativo; "em determinadas práticas pedagógicas", expressão delimitadora; "atividades tradicionais", avaliativo. Os elementos modalizadores aqui presentes, oriundos da 'modalização na língua' (CASTILHO e CASTILHO, 1993), podem ser concebidos como formas de orientar o texto para a maneira como o texto deve ser lido. Por fim, como nas demais análises, o locutor aprova E1, pois entende a existência de tal ponto de vista, e identifica-se com E3 e E4, pelo fato de ter tais pontos de vista como certos.

\section{CONSIDERAÇÕES FINAIS}

Ao longo do nosso texto, observamos, por meio das análises de enunciados presentes no interior do resumo acadêmico, que a presença do operador "entretanto" constitui uma forma de o locutor efetivo do texto trazer para o seu discurso a presença de outras vozes, outras personagens, com as quais ele pode se identificar, concordar ou rechaçar. Observamos ainda que o rechaço, dependendo da intenção do locutor do texto, pode ser total (nos casos em que as 
conclusões elaboradas em E2 e E4 são totalmente contrárias) ou parcial (nos casos em que as conclusões elaboradas em E2 e E4 não são totalmente contrárias, mas se completam de alguma forma).

Dessa forma, pensamos ser de fundamental importância repensar uma possível classificação para determinadas estruturas linguísticas bem como refletir sobre a existência de definições herméticas e funções fixas para certas estruturas, uma vez que no próprio uso argumentativo que fazemos da língua(gem) certas estruturas extrapolam comportamentos predeterminados pelas gramáticas tradicionais.

Como vimos nas análises aqui empreendidas, o elemento "entretanto", que é denominado de conjunção adversativa, cuja função é a de ligar ou unir termos equivalentes sintaticamente, no uso concreto da língua é responsável por ativar polifonia de enunciadores nos enunciados, permitindo ao locutor (usuário da língua) estabelecer outros sentidos/funcionamentos para essas palavras, além de demarcar o seu posicionamento diante do conteúdo apresentado.

\section{THE ESTRUCTURE “ENTRETANTO” IN THE ABSTRACT ACADEMIC GENRE: FROM ADVERSATIVE CONJUNCTION TO POLYPHONY ACTIVATOR ELEMENT}

ABSTRACT: The present paper aims at analyzing the linguistic structure entretanto in four academic abstratcs. For this research, we use the Theory of Argumentation in the Language Anscombre and Ducrot (1994) and Ducrot (1988), among others. In this theory, this operator works as an advisor of the discourses that allows the reader to produce certain conclusions. The analysis of the corpus found that the use of the argumentative operator entretanto, in the academic abstract genre, is presented as the main argumentative strategy. Besides that, the analyzed operator does not only function as an element of linking words and statements, but also activates different points of view, revealing the position of the locutor who is responsible for the text.

KEYWORDS: Argumentation. Argumentative operators. Academic abstract genre. Polyphony.

\section{REFERÊNCIAS}

ANSCOMBRE, Jean-Claude; DUCROT, Oswald. La argumentación en la lengua. Versión española de Julia Sevilha e Marta Tordesillas. Madrid: Editora Gredos, 1994.

BAKHTIN, Mikhail [1895-1975]. Problemas da Poética de Dostoievsky. Tradução por Paulo Bezerra. Rio de Janeiro: Editora Forense-Universitária, 1981. Tradução de Problemi poétiki Dostoiévskovo. [2 edição:1997]. 
. Estética da criação verbal. Tradução de Maria Ermantina Galvão G. Pereira. São Paulo: Martins Fontes, 2000.

BECHARA, Evanildo. Moderna gramática portuguesa. Rio de Janeiro: Nova Fronteira, 2009.

CASTILHO, A. T.; CASTILHO, C. M. M. de. Advérbios modalizadores. In: ILARI, Rodolfo (Org.) Gramática do Português Falado, Vol. II: Níveis de Análise Linguística. Campinas: Editora da Unicamp, 1993.

DUCROT, Oswald. O dizer e o dito. Campinas - São Paulo: Pontes, 1987.

Polifonia e argumentação: Conferencía del Seminário Teoria de la Argumentación y Analisis del Discurso. Cali, Universidad del Valle, 1988.

ESPÍNDOLA, Lucienne C. A entrevista: um olhar argumentativo. João Pessoa: Editora Universitária, 2004.

GUIMARÃES, Eduardo. Texto e argumentação: um estudo de conjunções do Português. Campinas. São Paulo: Pontes, 1987.

KOCH, I. G. V. A coesão textual. São Paulo: Contexto, 1999.

Argumentação e linguagem. São Paulo: Cortez, 2004.

. A inter-ação pela linguagem. São Paulo: Contexto, 2007.

MOTTA-ROTH, D.; HENDGES, G. R. Produção de Texto na Universidade. São Paulo: Parábola Editorial: 2010.

NICOLA, José de; INFANTE, Ulisses; Gramática Contemporânea da Língua Portuguesa. São Paulo: Editora Scipione, 1997.

SILVA, J. Q. G.; MATA, M. A. Proposta tipológica de resumos: um estudo exploratório das práticas de ensino da leitura e da produção de textos acadêmicos. In. Revista Scripta, v.6 n.11, p. 123-133. Belo Horizonte: PUC Minas, 2002.

SILVA, Marcos Antônio da. Os operadores de contraposição no gênero resumo acadêmico: perspectiva linguístico-discursiva. Tese (Doutorado) - UFPB/CCHLA. João Pessoa, 2015.

VOGT, Carlos; DUCROT, Oswald. De magis a mas: uma hipótese semântica. In: VOGT, Carlos: Linguagem, pragmática e ideologia. São Paulo: HUCITEC, 1980.

Data da Submissão: 26/02/2018

Data da Aprovação: 26/07/2018 